\title{
TRADUZIR O HEBRAICO DA PERIFERIA - MISSÃO POSSÍVEL? ${ }^{1}$
}

\section{TO TRANSLATE PERIPHERY HEBREW - IS IT A POSSIBLE MISSION?}

\author{
Nancy Rozenchan*
}

\begin{abstract}
Resumo
O presente texto atem-se a dificuldades enfrentadas por tradutores do hebraico ante textos cuja linguagem é aqui qualificada como linguagem de periferia. São considerados periferias, para esse fim, grupos cuja língua falada não é aquela considerada central no hebraico contemporâneo. Estão incluídos alguns modelos de linguagem de periferia, quais sejam a forma de expressão utilizada por religiosos e a de falantes com uso pobre da norma culta usuários com escolaridade insuficiente, nativos e imigrantes. No caso da imigrante, foi selecionada uma falante originária do Marrocos, com particularidades trazidas do árabe e do árabe-judaico que vigeu naquele país. A exposição de alguns modelos aponta para a impossibilidade de obter uma tradução que realmente enuncie as nuances e impacto cultural particulares expressos por estas periferias.
\end{abstract}

Palavras-chave: Tradução do Hebraico, Linguagens de Periferia, Linguagem de Religiosos, Linguagem de Marroquinos.

\begin{abstract}
This text aims to point at difficulties faced by Hebrew language translators in texts here described as produced in periphery language. For this purpose I mention groups whose spoken language is not considered as central in contemporary Hebrew. Some models of periphery language were included, namely the form of expression used by religious groups and by speakers with poor use of standard norms - native and immigrant speakers with insufficient education. In the case of immigrants, a native Moroccan speaker, with

\footnotetext{
${ }^{1}$ Este artigo é uma adaptação da aula que Nancy Rozenchan ministrou em 2015, no curso de tradução promovido na USP pelo CITRAT e pela Casa Guilherme de Almeida.

* Professora Sênior de Língua e Literatura Hebraica da Faculdade de Filosofia, Letras e Ciências Humanas da Universidade de São Paulo e tradutora de literatura hebraica.
} 
particularities brought from Arab and Jewish-Arab languages spoken in that African country was selected. The presentation of some models points to the inability to obtain a translation that can really expose the nuances and particular cultural impact expressed by the language of these peripheries.

Keywords: Translation from Hebrew, Periphery Languages, Religious People's Language, Language of Moroccan Jews. 
Quem procura uma loja de eletrônicos em Nova York e encontra a loja B@H mal sabe que esse nome não aponta para sócios cujas iniciais sejam B e H. B@H é um nome hebraico, indicando as iniciais das palavras brachá e hatslachá, que, na verdade, são pronunciadas na forma de leitura ashquenazita, bróche e hatslóche. Traduzindo os dois substantivos, obtemos bênção e sucesso. Imagino que é o que os donos desejam para si e querem compartilhar com seus inúmeros clientes. Porém, o que esse nome comercial tem a ver com a periferia do hebraico? E com tradução? E de qual periferia se trata?

O hebraico é uma língua muito antiga. É nela que foi escrita a Bíblia hebraica, obra em que a língua não é denominada de hebraico, mas de língua de Judá ou língua de Canaã. Quase desapareceu na sua forma falada, mas foi revivificada no século XIX, tornando-se, no século XX, a língua oficial de Israel. Convém, então, apresentar algumas particularidades suas, para que se entenda a denominação hebraico da periferia, com referência apenas aos séculos XX e XXI.

Devido à dispersão do povo hebreu durante muitos séculos, com núcleos em diversos continentes e países, o hebraico sofreu alterações fonéticas, fonológicas, morfológicas, sintáticas, semânticas e lexicais, cujas marcas são perceptíveis. Cabe acrescentar que, sendo considerada uma língua sagrada, ela tem papéis que extrapolam o da simples comunicação ou utilização para todos os tipos usuais de expressão.

Ainda, tendo vivido em terras diversas e entre diferentes povos, os judeus assimilaram línguas locais, utilizadas, principalmente, na comunicação oral ampla. Em paralelo, os judeus desenvolveram línguas próprias, que resultavam da mescla, em escalas variadas, entre o hebraico e línguas locais e que nem sempre seguiram um padrão amplo de desenvolvimento, visto que a língua estrangeira básica assimilada era preservada em estágio mais antiquado e estagnado.

As línguas judaicas mais conhecidas hoje são o ídiche e o ladino ou judeu-espanhol. Do período babilônico, conservou-se o aramaico judaico. Mas há muitas outras línguas judaicas, algumas quase totalmente desaparecidas. Uma exceção de uso de língua judaica que está encolhendo ocorreu recentemente: o filme israelense Adeus, Bagdá, de 2014, é encenado em uma dessas línguas que estão desaparecendo, a língua judeu-iraquiana, uma língua árabe particular, de uso local, com traços diversos da cultura judaica.

De volta ao primeiro exemplo, ele é compreensível para qualquer um que fale a língua hebraica ou saiba consultar um dicionário (de siglas, de preferência). Trata-se de uma 
expressão usual dos grupos religiosos e ultraortodoxos judaicos, conhecidos como haredim, ainda que não exclusiva deles. Com respeito à santidade da língua hebraica, há muitos ultraortodoxos que não a falam; somente a utilizam para o estudo de textos sagrados que foram escritos nela e, quando a leem ou fazem alguma citação, pronunciam-na na cadência ashquenazita, em que, em relação ao hebraico coloquial contemporâneo, há sons diferentes para algumas das vogais e consoantes, assim como uma acentuação tônica que diverge da pronúncia hodierna da língua.

Os grupos religiosos e, principalmente, os ultraortodoxos judaicos, falantes ou não do hebraico, têm em seu léxico um rico vocabulário que denota a sua condição de crentes e estudiosos dos preceitos divinos. Essa não é a única característica de sua forma de expressão, mas a que selecionamos para o momento. Assim, o nome comercial, trazido do contexto religioso, expressa um modo de comportamento específico usual naquele universo. Bênção e louvor aos méritos alheios são norma nesse hebraico. Os encômios se repetem e se sobrepõem em doses excessivas. Eles não causam problemas maiores na tradução, ainda que muitos outros vocábulos e expressões dessa linguagem apresentem dissonâncias em comparação com o hebraico coloquial e levem a traduções insatisfatórias.

Na prática, o nome do estabelecimento comercial, por ser apresentado como uma sigla um uso comum nesse segmento de utilização do hebraico -, naturalmente, complica a compreensão, como se pode observar no modelo que se segue.

Há algum tempo, um vídeo noticioso do mundo ultraortodoxo israelense, publicado pelo jornal Yediot, tratou da singularidade de um dos principais rabinos israelenses do universo mais fechado. O Rabino Chaim Kanievsky, então com 87 anos, vivia imerso nos estudos dos textos sagrados e na prática da caridade. Pessoas vinham a ele pedir uma bênção e lhe entregavam donativos. Ele, naturalmente, as saudava, e a bênção era a já mencionada: "bênção e sucesso". Mas, pronunciada do modo como ele o fazia, sequer os israelenses comuns, que não eram do seu universo, a compreendiam. Assim, foi preciso que o repórter explicasse e dissesse que se tratava de uma saudação, e não de algo mais estranho. Talvez pela idade ou para atender mais rapidamente os que o procuram, a bênção era abreviada e passava a ser expressa com a palavra bua. A cada um ele repete: “bua, bua” (NACH'SONI, 2015). É de se imaginar que ele se comunicava usualmente em ídiche e, por meio da abreviatura, não precisava fazer uso de palavras hebraicas inteiras. Como tradutora, imagino em que grave erro eu poderia incorrer se não procurasse saber por que um rabino idoso saúda 
alguém com a expressão bua, bua. A reportagem frisou que ele estava tão imerso nos estudos que sequer reconhecia os seus familiares, de tão distante que se mantinha dos assuntos mundanos.

Podemos deixar isso de lado. Alguém que lide com ficção hebraica raras vezes deverá se preocupar com a linguagem de periferia, pois ultraortodoxos sequer sabem que existe um campo de literatura que não seja produzida para fins religiosos. A dificuldade surgirá se algum escritor resolver incluir alguma citação da linguagem de religiosos.

Um segundo caso: há mais de vinte anos, quando traduzi o romance epistolar $A$ caixa preta, de Amós Oz, leitores admiraram-se pelo resultado obtido na tradução - em particular, pelas cartas do jovem sensível e que fugiu da escola, Boáz, israelense nativo, com a sua escrita repleta de erros de grafia ou concordância. Parece-me que jovens sensíveis e que fogem da escola podem escrever de forma semelhante em qualquer parte do mundo - ao menos, do ocidental, com o qual tenho mais contato. Para traduzir, contei quantos erros havia em cada carta ou bilhete do personagem, avaliei o caráter dele e busquei, então, formular erros em português da mesma categoria, em igual número aos existentes no original. Não foram erros nas mesmas palavras correspondentes ao hebraico, e, sim, nos lugares em que foi possível utilizar o critério. Simples assim. O resultado agradou. A bela escrita era de Amós $\mathrm{Oz}$, e não minha. Traduzir, para mim, é transferir para outra língua, transpondo toda a sensibilidade que a língua de origem despertou.

Entretanto, esse modelo de simplicidade não tem uso amplo, já que, em inúmeros casos, diversos fatores chegam até a impedir a reprodução do que a linguagem do texto original propôs. O modelo exposto a seguir, referente a um determinado nível do hebraico de periferia - e, aqui, periferia tem um sentido mais amplo, abrangendo a parcela da população que compõe a periferia geográfica e socioeconômica -, baseia-se no romance de Sara Shilo, Shum gamadim lo yavou [Nenhum duende vai aparecer], de 2006. Já me referi, em outras ocasiões, a esse livro, o qual não foi traduzido para o português ${ }^{2}$. Outro estudioso local, Damian

\footnotetext{
${ }^{2}$ Nos seguintes textos, abordei a obra mencionada: 1. ROZENCHAN, Nancy. Representação contemporânea do marroquino na literatura hebraica. Arquivo Maaravi (UFMG), Belo Horizonte, v. 4, n. 6, 2011. Disponível em: $<$ http://journaldatabase.info/articles/representacao_marroquino_na_literatura.html $>$ | 2. ROZENCHAN, Nancy. Do estudo aos sabores do Oriente: um ângulo da literatura hebraica contemporânea. Angulo, n. 120, Lorena, p. 27-37, 2010. Disponível em: <http://www.fatea.br/seer/index.php/angulo/article/viewFile/752/513> | 3. ROZENCHAN, Nancy. Traços de personagens bíblicos na construção de personagens discriminados na literatura hebraica contemporânea. Cadernos de Língua e Literatura Hebraica, v. 9, São Paulo, p. 13-31, 2011. | 4. ROZENCHAN, Nancy. Kavim shel guiborei hatanach bivniyat dmuyot shel mekupachim beShum gamadim lo yavou leSara Shilo [Traços de personagens bíblicos na construção de pessoas discriminadas em Nenhum duende vai aparecer, de Sara Shilo. Hador, hashnaton haivri shel America. Los Angeles, 2012, p. 147-153.
} 
Dzienciarsky, também se referiu a ele $^{3}$, um livro premiado que se destaca tanto pela trama como pela linguagem. Como há mais a acrescentar a respeito de sua linguagem, decidi compartilhar esses conhecimentos neste artigo, pois servirão para indicar que, por maior que seja o esforço envidado na tradução, ela não tenderá a abranger a totalidade do que a autora escreveu em hebraico. Tal realidade é lamentável, sim, mas serve para confirmar que uma tradução nem sempre pode equivaler ao original, não por deficiência de quem traduz, mas, simplesmente, porque se trata de um fato previsto e intransponível, devido às características inerentes a certos textos.

O romance de Sara Shilo narra a história de uma família israelense de origem marroquina que vive em uma cidade da periferia, na fronteira norte de Israel, sob constante ameaça de ataques de katyushas. Aparentemente situado nas décadas de 70 ou 80 do século passado, o romance é estruturado em uma série de monólogos que descrevem as vidas, pensamentos e planos de uma família que vive à sombra dos foguetes destruidores, tendo como pano de fundo a morte do pai, ocorrida repentinamente seis anos antes, deixando desamparada a antes bem posta família. O primeiro monólogo - o do hebraico mais imperfeito - é o da mãe, Simona, nativa do Marrocos, que trabalha como cuidadora em uma creche. Ele é seguido por um monólogo duplo de dois dos filhos, Dudi e Chayim - um deles, deficiente físico; e o outro, supridor de parte de suas deficiências. Eles tramam os modos de se enfrentarem os foguetes e aqueles que os lançam. O terceiro monólogo é de Kobi, o filho mais velho, que assume o papel do falecido pai e que sonha com um bom apartamento em outra cidade e em deixar para trás a vida miserável ou quase miserável que sua família leva. $\mathrm{O}$ livro se encerra com um monólogo da irmã que frequenta a escola e tem uma educação melhor, Eti, a qual deseja, cada vez mais, aprimorar o seu linguajar e a sua fala. Seu monólogo não apresenta a mesma linguagem usada pelos demais. Todos os filhos são israelenses nativos. Citações de membros da família, parentes e conhecidos da cidade e de locais próximos estão intercaladas nos monólogos. Além da temática da vida precária e do medo que, devido aos ataques de foguetes, assola parcialmente a família, o livro destaca-se pela estrutura sustentada pelos diversos monólogos e pela linguagem distante da norma culta, mas extremamente rica, com forte presença de solecismos - motivo que me leva a mencioná-

\footnotetext{
${ }^{3}$ Cf. DZIENCIARSKY, Damian Alejandro. A extraposição no hebraico - um fenômeno linguístico do idioma ou discriminação dos judeus da comunidade oriental. $198 \mathrm{f}$. Tese de doutoramento - Faculdade de Filosofia, Letras e Ciências Humanas, Universidade de São Paulo, São Paulo. 2012. Disponível em $<$ http://www.teses.usp.br/teses/disponiveis/8/8158/tde-08012013-144053/en.php>.
} 
lo aqui. A partir do título e até a penúltima parte, praticamente não há uma única frase em hebraico escorreito. Ao mesmo tempo, o romance é caracterizado por uma rica virtuosidade literária.

Solecismos e fenômenos correlatos são bastante conhecidos na língua hebraica. A população judaica e rarefeita que vivia em Israel há cem anos foi rapidamente incrementada com segmentos de população provenientes de países e formações culturais e gerais diversos. Cabe ressaltar que a população nativa de então mal se expressava em hebraico e, conforme o setor de origem ou convivência, acumulava o uso de línguas judaicas, o árabe e línguas europeias - principalmente, russo, alemão, romeno, polonês, francês e inglês. Os recémchegados, em todos os momentos do século XX, trouxeram suas respectivas bagagens linguísticas e culturais, que foram, então, se sobrepondo àquelas que estavam sendo sedimentadas. Como o hebraico - estagnado durante séculos, sobretudo no campo lexical precisou ser abastecido de novos materiais, foi inevitável que se nutrisse das diferentes matrizes trazidas, destacando-se, entre elas, o ídiche, o árabe e o russo. Além do léxico, vários outros aspectos foram assimilados dessas línguas. Considerando-se que, até poucos anos atrás, continuaram a afluir ao país ondas de imigrantes, algumas delas de consideráveis proporções, os fenômenos de absorção, assimilação, contágio e outros se mantiveram presentes na língua hebraica coloquial. Iêmen, Marrocos, Iraque, Síria, Irã, Tunísia, Líbia, Líbano, Egito contribuíram com as respectivas línguas árabes e árabes judaicas, no caso de estas terem existido e se preservado. Às populações provenientes da Europa atribui-se outra grande parcela de influências, à qual se deve acrescer o ladino, o judeu-espanhol. Em décadas mais recentes, pode-se registrar o am'hari, trazido da Etiópia, e, de novo, o russo e mais outras línguas dos diversos países que, anteriormente, compuseram a extinta União Soviética.

O judeu-árabe é um etnoleto, uma entidade linguística com história própria e usada por uma comunidade de língua distinta. Influenciado por diferentes períodos do árabe, tem-no por base, assim como dialetos locais e componentes hebraicos e aramaicos que não são restritos à esfera do vocabulário cultural específico, pois são encontrados no léxico, fonologia, morfologia e sintaxe. Tem empréstimos, ainda, do espanhol, ladino, francês e haquetia. $\mathrm{O}$ judeu-árabe marroquino tem parentesco com o mesmo etnoleto da Tunísia. 
Dentre os que trataram do livro de Shilo do ponto de vista filológico, destacam-se os israelenses Ruvik Rosenthal, Rifka Bliboim e Yehudit Henshke ${ }^{4}$. Esta última abordou várias características da escrita de Sara Shilo que podem ser apreciadas a partir da influência do judeu-árabe marroquino contida na expressão hebraica. Não se trata só de palavras ou expressões, mas da maneira como a utilização do hebraico, particularmente por Simona Dadon, a mãe da família, reflete o uso e a inflexão de sua língua original do continente africano.

No tema da semântica e léxico, destacam-se, por exemplo, o sentido diferente de alguns verbos, nem sempre transparentes, porque, apesar de se basearem em raízes conhecidas, não existem naquele bin'yan, naquela construção verbal do hebraico contemporâneo. Esse uso denota um calque tomado ao árabe ou ao judeu-árabe. $\mathrm{O}$ verbo hebraico é formado a partir de uma raiz - na maioria das vezes, constituída por três consoantes, uma das características das línguas semíticas. Existem, em hebraico, sete bin'yanim, os quais conferem um significado particular ao verbo utilizado em cada uma dessas estruturas, ainda que a raiz seja a mesma. Dificilmente, um mesmo verbo é encontrado em todas essas formas. Transportar o que o verbo significa em uma construção verbal para elaborar uma nova forma resulta mais em erro do que em neologismo. Assim, Simona utiliza o verbo lakum [levantar-se, também no sentido de acordar, levantar-se da cama]. Com a utilização de uma forma de construção diversa da raiz desse verbo [mekimot otam], inexistente, Simona indica que, no trabalho, tirará a criança do berço ou a acordará. A forma é compreensível pelo próprio contexto. Mas é claro que a tradução deverá deixar de lado qualquer traço daquele uso inadequado da construção verbal inexistente. Do mesmo verbo, lakum, temos mais um modelo do uso inadequado: "Mesmo quando o cobertor cai no chão, não coloco de volta neles para que não me se levantem". Tentei manter um pouco do erro na parte final da frase. Nesse caso, acentuo também o uso do pronome me. Um exemplo semelhante pode ocorrer em português: "Não me vá cair". Todavia, se essa possibilidade for utilizada na tradução, jamais levará o leitor a perceber que a forma empregada é a tradução do original, e não uma possibilidade do uso vulgar do português.

\footnotetext{
${ }^{4}$ Cf. 1. BLIBOIM, Rivka. MeHuckleberry Finn ad Shum Gamadim lo Yavou: Messirat dibur ivri tat-tikni betirgum uvamakor. In: BEN-SHACHAR, Rina; TURI, Guideon; BEN-ARI, Nitsa. (Ed.) Haivrit Safá Chayá: Kovetz mechkarim al halashon behekshereiha hachevratiim-hatarbutiim, vol. 5. Tel Aviv: Hakibuts Hameuchad, 2010, p. 87-108. 2. HENSHKE, Yehudit. Sara Shilo's No gnomes will appear: a linguistic analysis. Wisconsin, Hebrew Studies, vol. 54, p. 265-284, 2013. | 3. ROSENTHAL, Ruvik. Hazirá haleshonit: Bechiyatiyuni, chalas. Tel Aviv, Maariv, 1/3/2006. Disponível em: <http://www.nrg.co.il/online/1/ART1/054/793.html>.
} 
Outro exemplo da mesma categoria ocorre com o verbo lahafoch, que, nessa construção verbal, tem transformar-se como um dos seus significados. A personagem o usa na construção verbal que tem a forma do reflexivo e cujo significado é virar-se. Baseia-se, segundo Henshke, em um empréstimo semântico do árabe-judaico. Novamente, a tradução não indicará que se trata de um traço da particularidade da linguagem de uma pessoa proveniente do Marrocos.

Outro uso inadequado na linguagem de Simona é feito com o verbo laazov, que, basicamente, significa abandonar. Na sua fala, ele é utilizado no lugar do verbo que significa deixar.

Tradução de empréstimo do árabe-judaico e calque ocorrem também na esfera morfológica. No caso do verbo, é utilizada uma construção verbal que não existe para aquela raiz. Quanto a um exemplo de substantivo, um bom modelo é a palavra nachashá, forma feminina inexistente de nachash, significando cobra, baseada no árabe-judaico.

Devem, ainda, ser mencionados modelos na fraseologia, calques em expressões e combinações idiomáticas. Na sintaxe, destaca-se o uso de conjugações com verbos compostos: o verbo ser mais o particípio, como temos em português, fenômeno comum nesse dialeto. $\mathrm{O}$ resultado de uma tradução seria também o uso de dois verbos; todavia, o primeiro componente não seria o verbo ser: "costumavam ver", "costumava dizer" ou a redução para um vocábulo apenas, um pretérito simples, seriam as formas adequadas. Exemplos dessa categoria existem no hebraico coloquial contemporâneo, mas, na obra de Shilo, o verbo ser no passado aliado ao particípio não se diferencia do pretérito simples.

Tal uso do verbo composto tem sido denominado por alguns dos estudiosos de "dialeto dos desprivilegiados". Na realidade, o uso do verbo ser no passado seguido de particípio é pertinente ao próprio hebraico - em particular, ao sistema verbal do hebraico da Mishná. Deve-se registrar, simultaneamente, que essa é uma estrutura bastante difundida entre os falantes do árabe-judaico do norte da África. Segundo Henschke, a manifestação dessa forma entre falantes do hebraico da periferia, mas não entre falantes do hebraico israelense contemporâneo que estão expostos ao hebraico da Mishná, sugere que o árabe-judaico é a base do fenômeno da linguagem da periferia.

O uso inadequado de preposições também é uma das características dessa escrita. Ocorrem também omissões de preposições em expressões de tempo. 
É conveniente, ademais, acrescentar algumas observações para alguém que se proponha a traduzir do hebraico, a fim de que entenda o que é uma linguagem periférica usada por pessoas que vivem ou viveram de forma marginalizada. $\mathrm{O}$ que foi rapidamente exposto em relação ao livro de Sara Shilo pode ser avaliado em diversos outros escritores. Estudiosos como Yochai Oppenheimer e Rivka Bliboim, em um de seus registros (2012, p. 7-15), fazem outro tipo de proposta de análise de textos ficcionais, tentando identificar particularidades que podem ser úteis não só para o estudioso da ficção como para tradutores. É óbvio que, nas primeiras décadas do desenvolvimento da literatura hebraica em solo israelense, ainda antes da criação do Estado, escritores já se defrontaram com diversas línguas e linguagens periféricas. Durante várias décadas, a quase totalidade de escritores do país era ashquenazita. O que hoje se denomina de sefardita, em contraste com ashquenazita, é, na prática, a conjunção de sefarditas e mizrachim, ou seja, orientais ou, mais claramente, aqueles judeus provenientes de países árabes. Tomando somente o segmento mizrachi da classificação sefardita, deve-se lembrar que seu número no país, até a década de 1950, era pouco expressivo. Foi após a criação do Estado que imigrantes dessa denominação afluíram em massa ao país: foram, aproximadamente, 250 mil provenientes do Marrocos e mais de 100 mil provenientes do Iraque, além de grupos vindos de outras localidades. Para a parca população de então, essa mudança dramática na demografia local constituiu uma virada impressionante. Junto com a população árabe não judaica e a parcela de sobreviventes da Guerra oriundos da Europa, a literatura não pôde deixar de notar e registrar a presença mizrachi. E, com efeito, a literatura a registrou parcimoniosamente, usando suas falas em línguas outras, que não o hebraico, de forma discreta, moderada e em tom respeitoso. As referências não foram além de poucas palavras ou expressões, em que suas características particulares foram guardadas.

Openheimer e Bliboim, analisando essa temática, lembram que, durante várias décadas, semelhante tratamento linguístico foi feito pelos escritores ashquenazitas. Não existiam, então, praticamente autores mizrachim, os provenientes de países árabes. Quando estes despontaram nas décadas de 1970 e 80 - no caso, foram escritores nativos do Iraque, como Sami Michael, Shimon Ballas e Eli Amir -, foi-se notando, paulatinamente, uma mudança no trato da temática dos mizrachim e, principalmente, no tratamento da linguagem utilizada. À linguagem narrativa, em um hebraico escorreito, a linguagem falada dos diálogos contrapõese às particularidades de solecismo e erros diversos. Com o passar das décadas, isso foi se tornando mais comum e fluente. Atualmente, a segunda e terceira gerações de escritores 
mizrachim sente-se à vontade para escrever mais e mais nas linguagens das periferias linguística e social ou fazendo uso integral delas, como no caso de Shum gamadim lo yavou.

Oppenheimer e Bliboim chamam a atenção para as diferenças do tratamento que autores ashquenazitas e mizrachim deram e dão a essa questão, frisando as mudanças que vão ocorrendo desde o período em que os imigrantes quase não sabiam falar hebraico até começarem a se expressar com fluência e com erros. Esse registro passa, então, a constituir um interessante socioleto da sociedade israelense contemporânea. Tais fenômenos foram também registrados no cinema e no teatro israelenses, nos quais essas características foram exploradas mais intensamente, com tons de humor e até de deboche.

Feitas essas considerações, a sugestão para eventuais leitores e tradutores é que se avalie a época da escrita de determinada obra e o tom que lhe foi conferido pelo autor naquele momento. As diversidades, com base em socioletos, etnoletos, linguagens de desprivilegiados ou outras quaisquer, devem ser levadas em consideração, ainda que seja muito complexo tentar propor uma solução adequada para a sua tradução. 


\section{Bibliografia}

BLIBOIM, R. MeHuckleberry Finn ad Shum Gamadim lo Yavou: Messirat dibur ivri tat-tikni betirgum uvamakor. In: BEN-SHACHAR, R.; TURI, G.; BEN-ARI, N. (Ed.) Haivrit Safá Chayá: Kovetz mechkarim al halashon behekshereiha hachevratiim-hatarbutiim, vol. 5. Tel Aviv, Hakibuts Hameuchad, p. 87-108, 2010.

HENSHKE, Y. Sara Shilo's "No gnomes will appear": a linguistic analysis. Hebrew Studies, Wisconsin, vol. 54, p. 265-284, 2013.

NACH'SONI, K. Nayes sucot: harav Kanievsky shelo hikartem [Novidades de sucot: o Rabino Kanievsky que vocês não conheciam]. Yediot Acharonot, Tel Aviv, 26 de setembro de 2015. Disponível em: <http://www.ynet.co.il/articles/0,7340,L4704127,00.html>. Acesso em: 04 out. 2015.

OPPENHEIMER, Y.; BLIBOIM, R. Yitsug hadibur hamizrachi bassiporet haivrit. Haaivrit safá chaya, 6, p. 7-15, 2012.

ROSENTHAL, R. Hazirá haleshonit: Bechiyatiyuni, chalas. Maariv, Tel Aviv, 1/3/2006. Disponível em: <http://www.nrg.co.il/online/1/ART1/054/793.html> Acesso em: 01 dez. 2016.

SHILO, S. Shum gamadim lo iavou [Nenhum duende vai aparecer]. Tel Aviv: Am Oved, 2006. 